\title{
Systemic Markers of Inflammation in
} Smokers With Symptoms Despite Preserved Spirometry in SPIROMICS

\author{
Suresh Garudadri, BS; Prescott G. Woodruff, MD, MPH; MeiLan K. Han, MD; Jeffrey L. Curtis, MD; \\ R. Graham Barr, MD, DrPH; Eugene R. Bleecker, MD; Russell P. Bowler, MD, PhD; Alejandro Comellas, MD; \\ Christopher B. Cooper, MD; Gerard Criner, MD; Mark T. Dransfield, MD; Nadia N. Hansel, MD, MPH; \\ Robert Paine III, MD; Jerry A. Krishnan, MD, PhD; Stephen P. Peters, MD, PhD; Annette T. Hastie, PhD; \\ Fernando J. Martinez, MD; Wanda K. O'Neal, PhD; David J. Couper, PhD; Neil E. Alexis, PhD; \\ and Stephanie A. Christenson, MD
}

BACKGROUND: Chronic respiratory symptoms and exacerbation-like events are common among ever-smokers without airflow limitation on spirometry. The pathobiology of respiratory disease in this subgroup remains poorly defined, but may be due to underlying inflammation that overlaps with COPD or asthma. We hypothesized that symptoms, exacerbations, and functional measures of disease severity among smokers with preserved spirometry would be associated with markers of systemic inflammation, similar to what is reported in bone fide COPD, rather than elevated type 2 inflammation, which is often present in asthma.

METHODS: We measured inflammatory markers associated with COPD (C-reactive protein [CRP], fibrinogen, soluble tumor necrosis factor receptors [sTNFRSF1A and sTNFRSF1B], and blood/sputum neutrophils) and type 2 inflammation (IgE and blood/sputum eosinophils) in smokers with preserved spirometry (postbronchodilator $\mathrm{FEV}_{1} / \mathrm{FVC} \geq 0.70$ ) from the Subpopulations and Intermediate Outcome Measures In COPD Study (SPIROMICS). We evaluated the relationship of these markers with respiratory symptom burden (dichotomized by a COPD assessment test score cutoff of 10, diagnosis of chronic bronchitis), exacerbations, 6-minute walk distance, and lung function on the basis of $\mathrm{FEV}_{1}$.

RESULTS: CRP was associated with increased symptom burden (on the basis of COPD assessment test score and diagnosis of chronic bronchitis) and a greater number of exacerbations in the year before study enrollment. sTNFRSF1A was associated with symptom burden on the basis of COPD assessment test score. CRP and sTNFRSF1A levels negatively correlated with 6-minute walk distance. IgE and eosinophils were not associated with these outcomes.

CONCLUSIONS: Markers of inflammation including CRP and sTNFRSF1A are enriched among symptomatic smokers with preserved spirometry, suggesting an overlap with the underlying pathophysiology of COPD.

CHEST 2019; 155(5):908-917

KEY WORDS: bronchitis; COPD; C-reactive protein; smoking

FOR EDITORIAL COMMENT, SEE PAGE 886

ABBREVIATIONS: CAT $=$ COPD assessment test CRP $=$ C-reactive protein; $\mathrm{IQR}=$ interquartile range; $\mathrm{IRR}=$ incidence rate ratio; $6 \mathrm{MWD}=6$-minute walk test distance; TNF $=$ tumor necrosis factor; sTNFRSF $=$ soluble TNF receptor superfamily
AFFILIATIONS: From the Cleveland Clinic Lerner College of Medicine (Mr Garudadri), Case Western Reserve University, Cleveland, OH; Division of Pulmonary, Critical Care, Allergy, and Sleep Medicine ( $\mathrm{Mr}$ Garudadri and Drs Woodruff and Christenson), University of California, 
COPD is a heterogeneous respiratory condition that is a leading cause of morbidity and mortality worldwide. A postbronchodilator $\mathrm{FEV}_{1} / \mathrm{FVC}$ ratio $<0.70$ is required to confirm a COPD diagnosis. ${ }^{1}$ There is compelling evidence, however, that this diagnostic cutoff fails to capture the full breadth of smoking-related airway disease. Epidemiologic data from our group and others suggest that chronic respiratory symptoms are common among current and former smokers with preserved $\mathrm{FEV}_{1} / \mathrm{FVC}$ ratios $(\geq 0.70){ }^{2,3}$ These symptoms are associated with higher rates of COPD-like exacerbations, evidence of occult airway disease signified by reduced lung function, airway wall thickening on CT scan, a higher prevalence of chronic bronchitis, and elevated sputum mucin concentration. ${ }^{3,4}$

The underlying processes leading to symptoms and pathologic changes in these smokers with preserved spirometry remain uncertain. The molecular

San Francisco, San Francisco, CA; Division of Pulmonary and Critical Care Medicine (Drs Han and Curtis), University of Michigan, Ann Arbor, MI; Department of Medicine and Department of Epidemiology (Dr Barr), Columbia University, New York, NY; Department of Medicine (Dr Bleeker), University of Arizona, Tucson, AZ; Department of Medicine (Dr Bowler), National Jewish Health, Denver, CO; Department of Medicine (Dr Comellas), University of Iowa, Iowa City, IA; School of Medicine (Dr Cooper), University of California, Los Angeles, Los Angeles, CA; School of Medicine, Medicine/Pulmonary and Critical Care (Dr Criner), Temple University, Philadelphia, PA; Division of Pulmonary, Allergy, and Critical Care Medicine (Dr Dransfield), University of Alabama, Birmingham, Birmingham, AL; Johns Hopkins University (Dr Hansel), Baltimore, MD; Internal Medicine/Pulmonary and Critical Care (Dr Paine), University of Utah, Salt Lake City, UT; Pulmonary, Critical Care, Sleep and Allergy College of Medicine (Dr Krishnan), University of Illinois, Chicago, Chicago, IL; Section on Pulmonary, Critical Care, Allergy \& Immunologic Diseases (Dr Peters) and Center for Genomics and Personalized Medicine Research (Dr Hastie), Wake Forest University, Winston-Salem, NC; Department of Medicine (Dr Martinez), Weill Cornell Medical College, New York, NY; and Marsico Lung Institute (Dr O'Neal), Department of Biostatistics (Dr Couper), and Center for Environmental Medicine, Asthma and Lung Biology (Dr Alexis), University of North Carolina, Chapel Hill, NC.

FUNDING/SUPPORT: The Subpopulations and Intermediate Outcome Measures In COPD Study was supported by contracts from the National Institutes of Health (NIH)/National Heart, Lung, and Blood Institute [Grants HHSN268200900013C, HHSN268200900014C, HHSN268200900015C, HHSN268200900016C, HHSN268200900017C, HHSN268200900018C, HHSN268200900019C, HHSN268200900020C], and supplemented by contributions made through the Foundation for the $\mathrm{NIH}$ and the COPD Foundation from AstraZeneca/MedImmune; Bayer; Bellerophon Therapeutics; Boehringer Ingelheim Pharmaceuticals, Inc; Chiesi Farmaceutici S.p.A.; Forest Research Institute, Inc; GlaxoSmithKline; Grifols Therapeutics, Inc; Ikaria, Inc; Nycomed GmbH; Takeda Pharmaceutical Company; Novartis Pharmaceuticals Corporation; ProterixBio; Regeneron Pharmaceuticals, Inc; Sanofi; and Sunovion.

CORRESPONDENCE TO: Suresh Garudadri, Cleveland Clinic Lerner College of Medicine, Case Western Reserve University, 9500 Euclid Ave NA21, Cleveland, OH 44195; e-mail: sureshgarudadri@gmail.com Copyright (C) 2019 American College of Chest Physicians. Published by Elsevier Inc. All rights reserved.

DOI: https://doi.org/10.1016/j.chest.2018.12.022 mechanisms underlying this condition may be similar to those in COPD with confirmed airflow limitation and manifest as elevations in systemic biomarkers classically associated with COPD. Alternatively, type 2

inflammation, a predominant component of asthma, ${ }^{5}$ may be enhanced in this group, and manifest as elevations in biomarkers of type 2 inflammation. It is difficult to establish the contribution of asthma-like pathology to disease in this population of smokers at high risk for developing COPD. Furthermore, we have shown that type 2 inflammation can occur in COPD even without a prior diagnosis of asthma. ${ }^{6}$

To test these two competing hypotheses, we profiled blood and sputum inflammatory markers in ever-smokers with preserved spirometry in the Subpopulations and Intermediate Outcome Measures in COPD Study (SPIROMICS), ${ }^{7}$ from which we originally characterized the clinical significance of symptoms in this smoking population. ${ }^{3}$ We a priori selected inflammatory markers associated with COPD (including serum C-reactive protein [CRP], fibrinogen, soluble tumor necrosis factor [TNF] receptors, and blood/sputum neutrophils), ${ }^{8,9}$ and markers of type 2 inflammation (including IgE and blood/sputum eosinophils). We related these markers to symptom burden, exacerbations, and functional measures of disease severity.

\section{Methods \\ Study Participants and Definitions}

We used data from 830 ever-smokers with preserved spirometry enrolled in SPIROMICS, a longitudinal prospective cohort study. ${ }^{7}$ We defined preserved spirometry as an $\mathrm{FEV}_{1} / \mathrm{FVC}$ ratio $\geq 0.70$, and an FVC greater than or equal to the lower limit of normal. We categorized participants as symptomatic using the COPD assessment test (CAT), a validated eight-question health status tool, ${ }^{10}$ and by a study-defined diagnosis of chronic bronchitis. Consistent with our previous analyses and the Global Initiative for Chronic Obstructive Lung Disease criteria, we categorized participants with a CAT score $\geq 10$ as symptomatic. ${ }^{1,3}$ We defined chronic bronchitis as self-reported cough and phlegm on most days for at least 3 months per year, over a period of 2 years or more. ${ }^{11}$ We collected data on self-reported exacerbations retrospectively over the year before enrollment and prospectively over the study period. We defined exacerbations as the use of antibiotics, systemic glucocorticoids, and/or a health-care utilization event (office visit, ED visit, or hospitalization) for a respiratory symptom "flare-up." Historical data regarding asthma diagnoses were defined as "childhood asthma" for childhood diagnoses and "ever-asthma" encompassing both childhood and adult diagnoses. Participants with unstable cardiac disease were excluded. We collected information on comorbid cardiovascular conditions including hypertension, coronary artery disease, congestive heart failure, valve disease, and vascular disease. The study protocol was approved by the institutional review boards of all participating sites. All participants gave written informed consent. Additional details regarding the study protocol and institutional review board documentation are available in e-Appendix 1 and e-Table 1. 
Inflammatory Marker Measurements and Normalization Procedure

We collected complete blood counts with differential, sputum cell differential counts, and enzyme-linked immunosorbent assay-based measurements of serum IgE in all participants. We measured CRP, fibrinogen, and the soluble TNF receptor superfamily (sTNFRSF) members 1A (also known as sTNF-R55) and 1B (also known as sTNF-R75) in a subset of samples using Luminex-based multiplex assays $(\mathrm{n}=429) .{ }^{12,13}$ Raw measurements were log transformed and normalized by $z$ score (e-Appendix 1).

\section{Statistical Analyses}

We compared demographic and clinical characteristics across groups using $t$ tests and $\chi^{2}$ tests as appropriate. We fit logistic regression models to assess the relationships between inflammatory markers and symptoms. We used Wilcoxon rank sum tests to evaluate raw marker values and negative binomial regression to evaluate associations between inflammatory marker levels and exacerbations. Prospective exacerbations were modeled with an offset term of the natural $\log$ of total follow-up time to accommodate for variable follow-up time across participants. We fit linear regression models to relate inflammatory marker levels to 6-minute walk test distance (6MWD) and postbronchodilator percent of predicted $\mathrm{FEV}_{1}$. Adjusted multivariate models were fit with age, sex, BMI, race, current smoking status, smoking pack-years, baseline asthma history, study site, and assay batch as covariates. We used analysis of variance to evaluate differences in CRP between study strata, and Tukey-Kramer tests to evaluate pairwise comparisons. We compared baseline CRP measurements to 1year follow-up measurements using Pearson correlation and BlandAltman analyses. We defined statistical significance as $P<.05$. False discovery rate adjusted $P$ values were calculated using the BenjaminiHochberg procedure. ${ }^{14}$

\section{Results}

\section{Characteristics of Study Participants}

Among ever-smokers without airflow limitation $(\mathrm{n}=$ 830), 415 were symptomatic (CAT $\geq 10$ ) (Table 1$)$. Symptomatic participants were younger, had a higher average BMI, slightly lower lung function, and a marginally higher response to bronchodilators relative to participants without symptoms. A higher percentage of participants with symptoms were women, African American, and current smokers. The pack-year smoking history was higher among symptomatic participants. Symptomatic participants were more likely to have a history of asthma in both childhood and ever. There was no significant difference in $\mathrm{FEV}_{1} / \mathrm{FVC}$ ratio between these groups. Among the ever-smokers with preserved spirometry, 149 had chronic bronchitis. Participants with chronic bronchitis were younger, more likely to be current smokers, and more often had a history of asthma (ever). Lung function was slightly lower among participants with chronic bronchitis.

\section{Associations of Inflammatory Markers With Symptoms}

In unadjusted analyses, CRP and IgE were associated with increased odds of having symptoms defined by CAT score (Table 2). In adjusted analyses, CRP remained associated with worse symptoms (OR, 1.30; 95\% CI, 1.03-1.65; $P=.03$ ). The median raw CRP level among symptomatic participants was $3.6 \mu \mathrm{g} / \mathrm{mL}$ (interquartile range [IQR], 1.4-8.1) compared with 2.0 $\mu \mathrm{g} / \mathrm{mL}$ (IQR, 0.8-4.8) among participants without symptoms $(P<.001)$ (Fig 1$)$. Including history of cardiovascular disease as a model covariate did not affect the association between CRP and symptoms (OR, 1.30; 95\% CI, 1.02-1.66; $P=.03$ ). sTNFRSF1A was associated with symptoms in adjusted analyses only (OR, 1.33;
95\% CI, 1.03-1.75; $P=.03$ ). African American participants, who were more likely to be symptomatic (Table 1), had higher median IgE and lower median sTNFRSF1A levels compared with non-Hispanic white participants (e-Fig 1). Analyses stratified by race revealed no differences in IgE between symptomatic and asymptomatic participants (e-Fig 1A); however, higher sTNFRSF1A was associated with symptoms across both race strata (e-Fig 1B). This suggests that race confounded the relationship between IgE and symptom status, and negatively confounded the relationship between sTNFRSF1A and symptom status, explaining the effects of adjustments in models evaluating these markers. We assessed the possibility that including baseline asthma as a covariate in adjusted models attenuated the association between $\operatorname{IgE}$ and respiratory symptoms. In adjusted analyses with asthma history (ever) omitted as a covariate, IgE was still not significantly associated with symptoms (OR, 1.12; 95\% CI, 0.95-1.32; $P=.18$ ). We next evaluated the effect of current smoking intensity on the associations among CRP, sTNFRSF1A, and symptom status. In adjusted models with current smoking treated as a continuous variable (number of cigarettes smoked per day), both CRP and sTNFRSF1A remained associated with symptoms (CRP: OR, 1.30; 95\% CI, 1.03-1.65; $P=.03$, sTNFRSF1A: OR, 1.36; 95\% CI, 1.06-1.78; $P=.02)$.

In unadjusted analyses, CRP and blood neutrophil count were associated with increased odds of having chronic bronchitis. Following adjustments, CRP remained associated with chronic bronchitis (OR, 1.94; 95\% CI, 1.36-2.81; $P<.001)$. The median CRP value was higher among participants with chronic bronchitis compared with those without chronic bronchitis (5.9 $\mu \mathrm{g} / \mathrm{mL}$ [IQR, $1.7-10.8$ ] vs $2.4 \mu \mathrm{g} / \mathrm{mL}$ [IQR, 1.0-5.6], $P<$ .001) (Fig 1). 
TABLE 1 ] Characteristics of Study Participants

\begin{tabular}{|c|c|c|c|c|c|c|}
\hline Characteristic & $\begin{array}{c}\text { Asymptomatic } \\
(\text { CAT < 10) } \\
n=415\end{array}$ & $\begin{array}{l}\text { Symptomatic } \\
\qquad \begin{array}{c}\text { (CAT } \geq 10) \\
n=415\end{array}\end{array}$ & $P$ Value & $\begin{array}{c}\text { No Chronic } \\
\text { Bronchitis } \\
n=660\end{array}$ & $\begin{array}{c}\text { Chronic } \\
\text { Bronchitis } \\
n=149\end{array}$ & $P$ Value \\
\hline Age, y & $61 \pm 9.5$ & $59 \pm 9.8$ & $<.001$ & $60 \pm 9.6$ & $59 \pm 9.7$ & .03 \\
\hline BMI & $28 \pm 4.7$ & $30 \pm 5.1$ & $<.001$ & $29 \pm 5.1$ & $29 \pm 4.9$ & .56 \\
\hline Women & $199(48)$ & $236(57)$ & .01 & $337(51)$ & $88(59)$ & .08 \\
\hline \multicolumn{7}{|l|}{ Race } \\
\hline White & $322(78)$ & $231(56)$ & $<.001$ & $443(67)$ & 102 (69) & .94 \\
\hline African American & $72(17)$ & $158(38)$ & & $179(27)$ & $39(26)$ & \\
\hline Other & $21(5)$ & $26(6)$ & & $38(6)$ & $8(5)$ & \\
\hline Current smokers & $173(42)$ & $254(62)$ & $<.001$ & $316(48)$ & $100(68)$ & $<.001$ \\
\hline Smoking, pack-y & $40 \pm 20$ & $45 \pm 29$ & .008 & $42 \pm 26$ & $45 \pm 20$ & .11 \\
\hline History of asthma, ever & $30(7)$ & $102(26)$ & $<.001$ & $90(14)$ & $36(27)$ & $<.001$ \\
\hline $\begin{array}{l}\text { History of childhood } \\
\text { asthma }\end{array}$ & $14(3)$ & $40(10)$ & $<.001$ & $39(6)$ & $12(9)$ & .22 \\
\hline $\begin{array}{l}\text { History of } \\
\text { cardiovascular } \\
\text { condition }\end{array}$ & $218(53)$ & $266(64)$ & .001 & $374(57)$ & $96(65)$ & .09 \\
\hline Chronic bronchitis & $21(5)$ & $128(32)$ & $<.001$ & & & \\
\hline $\mathrm{CAT} \geq 10$ & & & & $272(41)$ & $128(86)$ & $<.001$ \\
\hline $\begin{array}{l}\text { Post-BD FEV }{ }_{1} \\
\% \text { predicted }\end{array}$ & $100 \pm 12$ & $96 \pm 13$ & $<.001$ & $99 \pm 13$ & $95 \pm 12$ & $<.001$ \\
\hline $\mathrm{FEV}_{1} / \mathrm{FVC}$ & $0.77 \pm 0.05$ & $0.77 \pm 0.05$ & .50 & $0.77 \pm 0.05$ & $0.77 \pm 0.05$ & .50 \\
\hline$\%$ BD reversibility & $6.0 \pm 5.3$ & $7.0 \pm 8.1$ & .03 & $6.3 \pm 6.4$ & $7.0 \pm 8.2$ & .32 \\
\hline $\mathrm{CRP}, \mu \mathrm{g} / \mathrm{mL}$ & $2.0[0.8-4.8]$ & $3.6[1.4-8.1]$ & $<.001$ & $2.4[1.0-5.6]$ & $5.9[1.7-10.8]$ & $<.001$ \\
\hline Fibrinogen, $\mathrm{mg} / \mathrm{mL}$ & $4.8[4.3-5.7]$ & $5.0[4.3-5.9]$ & .23 & $4.8[4.2-5.8]$ & $5.1[4.5-6.2]$ & .07 \\
\hline sTNFRSF1A, ng/mL & $1.6[1.3-2.1]$ & $1.7[1.3-2.2]$ & .27 & $1.7[1.3-2.1]$ & $1.6[1.3-1.9]$ & .19 \\
\hline sTNFRSF1B, ng/mL & $6.5[5.4-8.3]$ & $7.0[5.5-8.8]$ & .18 & $6.8[5.5-8.6]$ & $6.5[5.3-8.8]$ & .72 \\
\hline $\mathrm{IgE}, \mathrm{IU} / \mathrm{mL}$ & 35 [13-99] & $49[17-156]$ & .001 & $37[13-132]$ & $58[19-129]$ & .06 \\
\hline $\begin{array}{l}\text { Blood } \\
\text { neutrophils, } \times 10^{9} / \mathrm{L}\end{array}$ & $3.8[3.0-4.8]$ & $3.9[2.7-4.9]$ & .66 & $3.8[2.8-4.7]$ & $4.1[3.1-5.4]$ & .008 \\
\hline $\begin{array}{l}\text { Blood } \\
\qquad \text { eosinophils, } \times 10^{9} / \mathrm{L}\end{array}$ & $0.16[0.10-0.21]$ & $\begin{array}{c}0.18 \\
{[0.10-0.22]}\end{array}$ & .38 & $\begin{array}{c}0.18[0.10- \\
0.21]\end{array}$ & $\begin{array}{l}0.15[0.10- \\
0.22]\end{array}$ & .40 \\
\hline Sputum neutrophils, $\%$ & $66[40-83]$ & $66[43-80]$ & .86 & $66[43-81]$ & $65[41-82]$ & .95 \\
\hline Sputum eosinophils, \% & $0.21[0.00-0.76]$ & $\begin{array}{c}0.15 \\
{[0.00-0.66]}\end{array}$ & .34 & $\begin{array}{l}0.16[0.00- \\
0.74]\end{array}$ & $\begin{array}{l}0.24[0.00- \\
0.69]\end{array}$ & .46 \\
\hline
\end{tabular}

Clinical and demographic data are reported as mean \pm SD or No. (\%). Inflammatory markers are reported as median [interquartile range]. Participants with and without symptoms were compared using $t$ tests for continuous variables and $\chi^{2}$ tests for categorical variables. CAT $=$ COPD assessment test; $\mathrm{CRP}=\mathrm{C}$-reactive protein; \% BD reversibility $=$ percentage improvement in FEV1 following bronchodilator administration; post-BD FEV ${ }_{1}=$ postbronchodilator $\mathrm{FEV}_{1}$; sTNFRSF = soluble tumor necrosis factor receptor superfamily.

\section{Associations of Inflammatory Markers With Exacerbations}

We next investigated the relationship between inflammatory marker levels and exacerbations (Table 3). A total of 109 study participants had at least one exacerbation during the year before enrollment, with 171 exacerbations reported in total (e-Table 2). In unadjusted analyses, CRP and IgE were associated with retrospective exacerbations (Table 3). Following adjustments, only CRP remained associated with retrospective exacerbations (incidence rate ratio [IRR], 1.40; 95\% CI, 1.03-1.92; $P=.04$ ). CRP remained associated with past exacerbations when history of cardiovascular disease was included as an adjusted model covariate (IRR, 1.40; 95\% CI, 1.03-1.94; $P=.04$ ). In adjusted analyses with asthma history (ever) omitted as a covariate, $\operatorname{IgE}$ was still not associated with retrospective exacerbations. 


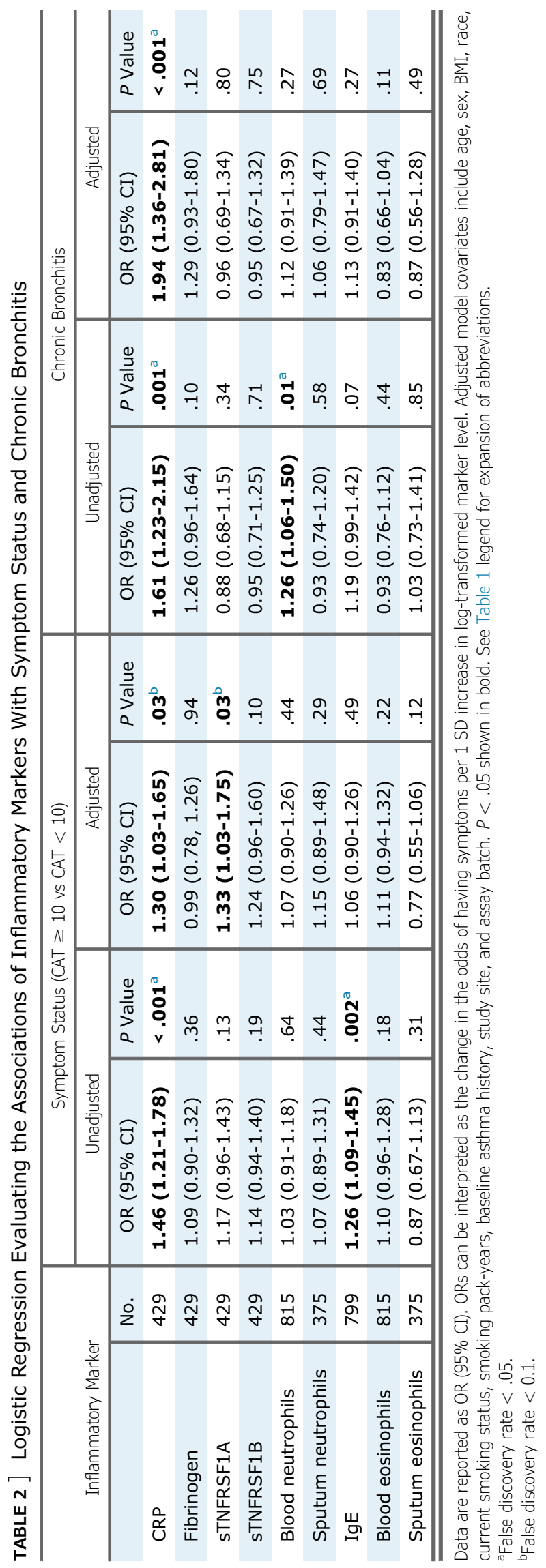

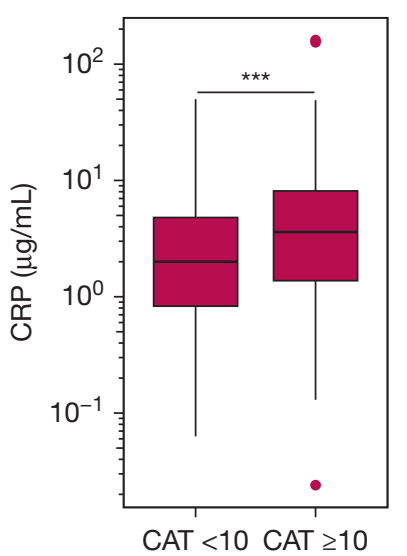

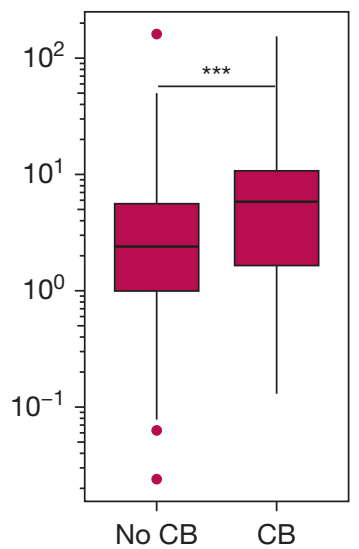

Figure 1 - CRP levels across participants with and without symptoms. Higher CRP levels were associated with respiratory symptoms defined by CAT score and diagnosis of chronic bronchitis. Box and whisker plots show median \pm interquartile (IQR) range. Horizontal lines represent the median value. The lower and upper limits of the rectangular box represent the 25th and 75 th percentiles. The lower and upper limits of the whiskers represent the upper and lower quartiles \pm 1.5 times the IQR. Outliers are shown as points. ${ }^{* *} P<.001$, calculated using the Wilcoxon rank sum test. $C A T=C O P D$ assessment test, $C B=$ chronic bronchitis.

Over the study enrollment period, 151 participants reported at least one exacerbation, with 330 reported in total. CRP was associated with prospective exacerbations in unadjusted analyses only (unadjusted IRR, 1.52; 95\% CI, 1.13-2.05; $P=.005$; adjusted IRR, 1.26; $95 \% \mathrm{CI}$, $0.88-1.80 ; P=.15)$.

\section{Associations of CRP and sTNFRSF1A With Measures of Disease Severity}

We next evaluated whether markers associated with symptoms were also associated with functional measures of disease severity such as 6MWD and $\mathrm{FEV}_{1}$ (e-Table 3). In adjusted analyses, CRP ( $\beta=-11.4 ; 95 \% \mathrm{CI},-19.7$ to $-3.1 ; P=.007)$ and sTNFRSF1A $(\beta=-12.2 ; 95 \% \mathrm{CI}$, -21 to $-3.4 ; P=.007)$ were negatively correlated with $6 \mathrm{MWD}$. These markers were not associated with $\mathrm{FEV}_{1}$ in adjusted analyses.

\section{CRP Levels Among Never Smokers and Across Time}

CRP demonstrated a consistent pattern across multiple outcomes, prompting us to evaluate comparisons with never-smoker healthy control patients, and its stability over time. The median CRP level was higher among symptomatic (CAT $\geq 10)$ smokers with preserved spirometry compared with never-smoker control patients $(3.6 \mu \mathrm{g} / \mathrm{mL}$; IQR, $1.4-8.1$ vs $1.7 \mu \mathrm{g} / \mathrm{mL}$; IQR, $0.9-4.0 ; P<.001$ ), but was not significantly higher in smokers with preserved spirometry without symptoms (2.0 $\mu \mathrm{g} / \mathrm{mL}$; IQR, $0.8-4.8$ vs $1.7 \mu \mathrm{g} / \mathrm{mL}$; IQR, 0.9-4.0; $P=$ .36). CRP levels among symptomatic smokers with preserved spirometry were comparable to CRP levels in 


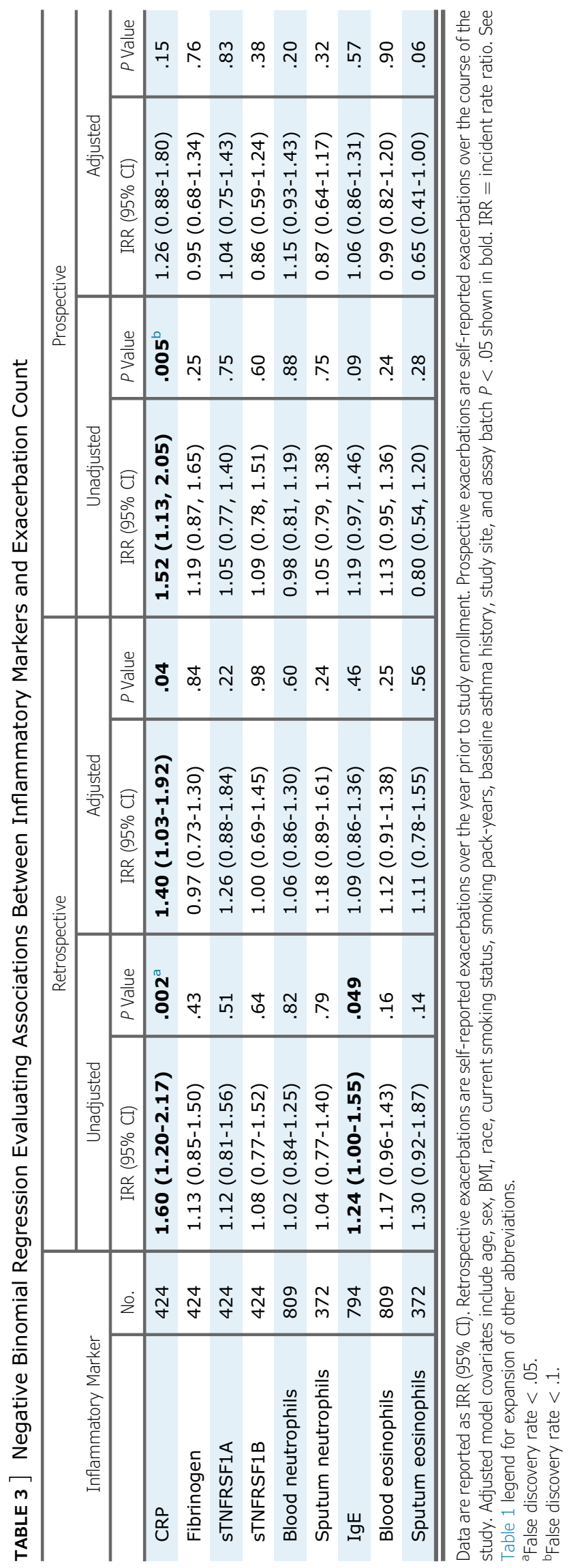

symptomatic participants with GOLD I or II COPD (Fig 2). Of the 175 never-smokers in SPIROMICS, 28 reported a CAT score $>10$. Among never-smokers, CRP was not significantly associated with symptoms (unadjusted OR, 1.38; 95\% CI, 0.89-2.21; $P=.15$; adjusted OR, 0.89, 95\% CI, 0.89-2.21; $P=.74)$. We assessed the stability of CRP over time among a subset of smokers with preserved spirometry with 1-year followup measurements available $(n=115)$. Among these participants, baseline levels of CRP correlated with 1year follow-up levels $(\mathrm{r}=0.67, P<.001)$ (Fig 3 ).

\section{Discussion}

COPD is heterogeneous, with some patients exhibiting persistent systemic inflammation, ${ }^{15}$ including elevations in blood inflammatory proteins such as CRP. Other patients with COPD display enhanced type 2 inflammation, including lung and blood eosinophilia. ${ }^{16}$ The relative contribution of systemic vs type 2 inflammation to disease burden among smokers with preserved spirometry remains uncertain. We demonstrate that markers of systemic inflammation, including CRP and sTNFRSF1A, are associated with respiratory symptoms, exacerbations, and activity limitation among ever-smokers who do not meet the current spirometric definition of COPD. Although symptomatic smokers with preserved spirometry are more likely to carry an "asthma" diagnosis, we find that markers of type 2 inflammation including IgE and blood/sputum eosinophils do not fully explain potential respiratory disease among this group. A subset of symptomatic smokers with preserved spirometry may have a response to smoke exposure that is pathologic and marked by systemic markers of inflammation that are classically associated with COPD.

Although CRP and sTNFRSF1A were associated with worse respiratory symptoms, their sources and relationships with possible ongoing pulmonary inflammation remain unclear. These markers may represent pulmonary inflammation that has "spilled" into systemic circulation ${ }^{17}$; however, data supporting this hypothesis in COPD are controversial because some studies have failed to demonstrate associations between inflammatory markers in the lung and plasma. ${ }^{17,18}$ Alternatively, systemic responses to smoke exposure may reflect an underlying predisposition toward developing inflammation, a hypothesis that may help explain why COPD is frequently associated with complex inflammatory comorbidities such as metabolic syndrome. ${ }^{19,20}$ Current smoking by itself can raise 


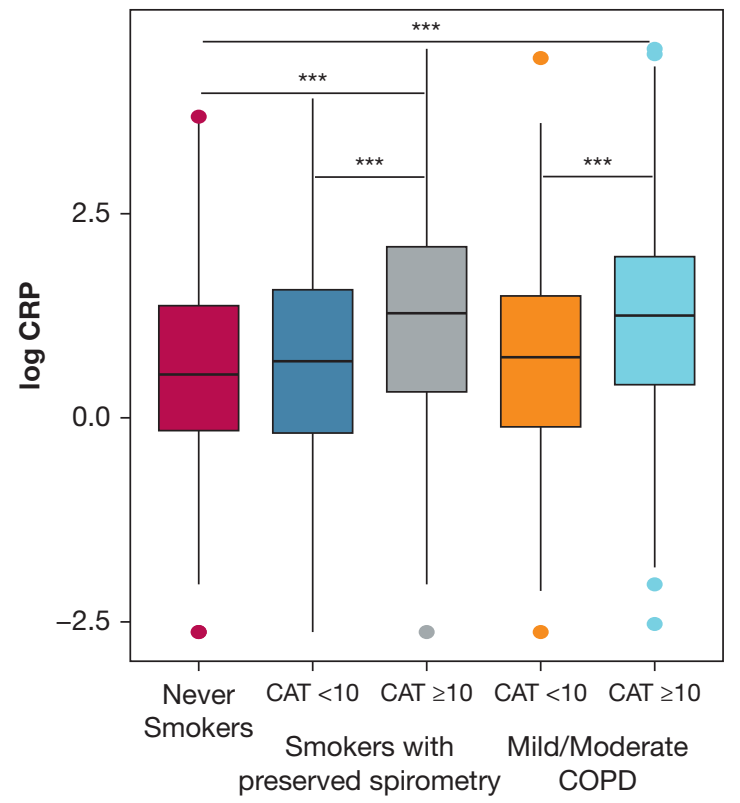

Figure 2 - Log transformed CRP levels across healthy participants and ever smokers with and without COPD. The median CRP level is higher among symptomatic smokers with preserved spirometry and symptomatic participants with COPD compared to their asymptomatic counterparts and never-smoker healthy control participants. Box and whisker plots show median \pm interquartile (IQR) range. Horizontal lines represent the median value. The lower and upper limits of the rectangular box represent the 25th and 75th percentiles. The lower and upper limits of the whiskers represent the upper and lower quartiles \pm 1.5 times the IQR. Outliers are shown as symbols. ${ }^{* *} P<.001$, calculated using the Tukey-Kramer method.

markers of inflammation ${ }^{21}$ and induce symptoms via irritation and increased mucus production. Markers of inflammation remained associated with increased symptoms even after adjustments for current smoking status, suggesting that current smoking does not fully explain the burden of symptoms and exacerbations among these participants. There is a well-characterized association between CRP and cardiovascular disease, ${ }^{22}$ and it is possible that respiratory symptoms in our data actually reflects underlying cardiac disease rather than respiratory disease. We demonstrate, however, that the association between CRP and respiratory symptoms is independent of cardiovascular comorbidities that are assessed historically.

Higher levels of CRP were associated with chronic bronchitis in this study. Chronic bronchitis is a hallmark feature of COPD, but is also common among current and former smokers without airflow limitation. ${ }^{11}$ Features believed to be central to chronic bronchitis include goblet cell metaplasia, ${ }^{23}$ leading to mucus overproduction and hypersecretion, increased airway mucin concentration, ${ }^{4}$ and reduced mucus clearance. ${ }^{11}$ These pathologic changes can arise from cigarette smoke
A

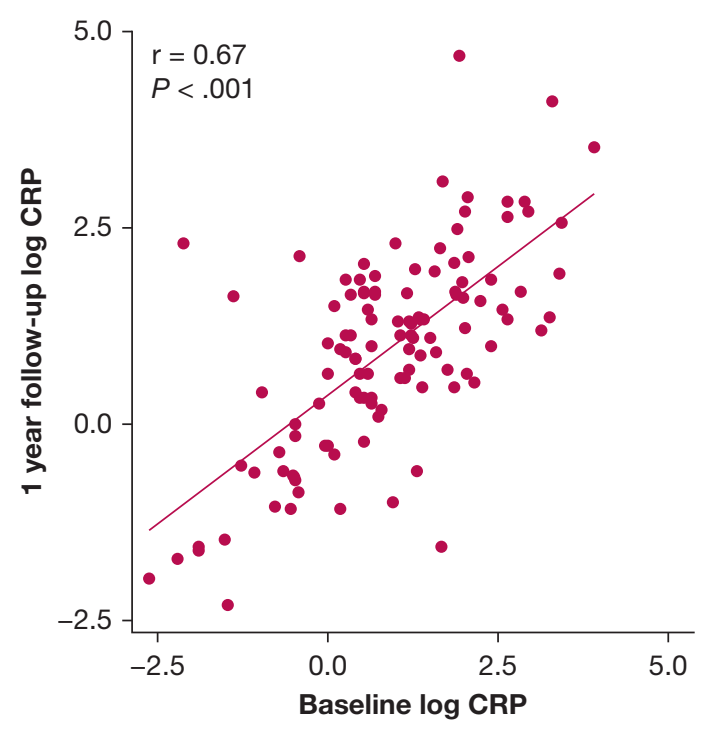

B

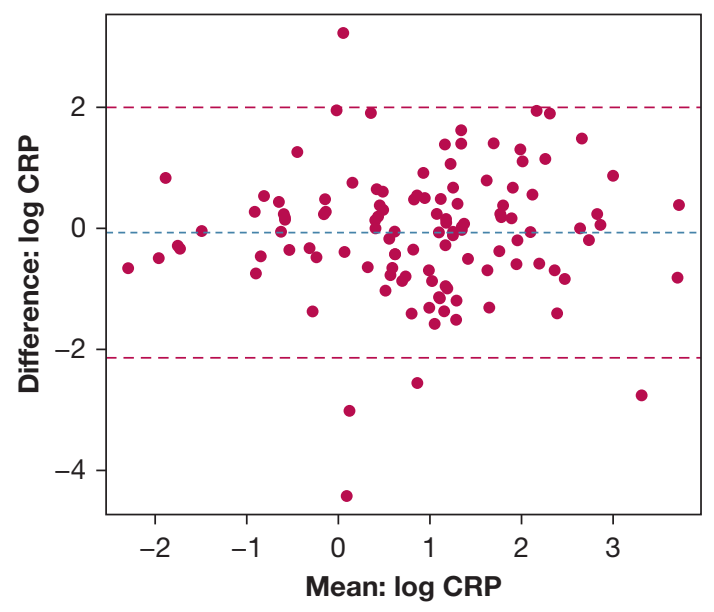

Figure 3 - Stability of log transformed CRP measurements over time among smokers with preserved spirometry. A, Baseline CRP measurements are significantly associated with 1-year follow-up measurements $(n=115) . B$, Bland-Altman plot showing mean difference in CRP measurement from baseline to 1-year follow-up against the mean of the two measurements. Blue dashed line: overall mean difference between baseline and follow-up measurements, red dashed lines: \pm one standard deviation from the mean.

exposure, infection, and immune cell-mediated processes. ${ }^{11}$ CRP was associated with chronic bronchitis even after adjusting for current smoking status; furthermore, participants with signs of an acute pulmonary infection were excluded from SPIROMICS, suggesting that chronic inflammatory processes underlie the symptoms of bronchitis in this group.

In COPD, CRP has been shown to predict exacerbations both as an independent marker ${ }^{24}$ and when simultaneously elevated with fibrinogen and leukocyte count. ${ }^{25}$ There remains a lack of consensus on the utility 
of CRP for exacerbation prediction in COPD, however, because CRP did not predict prospective exacerbations in an analysis of participants from the Genetic Epidemiology of COPD (COPDGene) and SPIROMICS cohorts. ${ }^{26}$ Among these previously uncharacterized unobstructed participants, we found that CRP was independently associated with exacerbations retrospectively but not prospectively. This raises the possibility that CRP reflects recent exacerbations in our data; however, CRP measurements in this study were obtained at least 6 weeks after the participants' last reported exacerbation.

CRP and sTNFRSF1A were associated with shorter $6 \mathrm{MWD}$, which is concordant with prior studies evaluating the relationship between CRP and functional limitation in COPD. ${ }^{27-29}$ CRP was not associated with $\mathrm{FEV}_{1}$; however, there was a narrow range of $\mathrm{FEV}_{1}$ values among these unobstructed participants.

There are limitations to this report. SPIROMICS was not population based, and may have recruited a biased proportion of current and former smokers who have symptoms in the absence of airflow limitation on spirometry. Further validation in population-based studies is needed to ensure generalizability. There were some technical challenges. Additional markers, including IL-6, IL-8, and TNF- $\alpha$, could not be characterized because of poor assay performance. Sputum cell differential data were only available in a subset of participants because of oral contamination (> $80 \%$ squamous cells) and failed cell differential stains.

In summary, among smokers with preserved spirometry, CRP and sTNFRSF1A were associated with clinical evidence of airway disease including respiratory symptoms, chronic bronchitis, exacerbations, and activity limitation. Our findings suggest that these systemic markers reflect the presence of underlying inflammation that is pathologic and similar to what occurs in a subset of patients with COPD. This adds to the growing body of evidence that smoking-related airway disease extends beyond the spirometric definition of COPD, potentially representing a continuum with common pathobiologic features. It remains unclear whether symptomatic smokers with preserved spirometry are in an early stage of disease that will eventually progress to overt COPD with airflow limitation or whether they have a different stable smoking-related condition with similar underlying inflammation. ${ }^{30}$ If it is the former, then this may be a group to target with disease-modifying interventions that prevent disease progression. A recent study of lung tissue samples found that in mild to moderate COPD there is a substantial loss of small airways, undetectable on clinical CT and independent of emphysema. ${ }^{31}$ Extensive structural pathology may be therefore present in COPD before significant lung function decline is even identified. As current diagnostics cannot identify these changes, the use of other strategies (eg, biomarkers and clinical symptoms as examined in the present study) to identify the patients that may benefit from early disease-modifying therapies will likely be necessary. Overall, this also highlights the need for longitudinal studies evaluating the clinical and biological trajectory of symptomatic ever-smokers to better characterize the natural history of their disease. 


\section{Acknowledgments}

Author contributions: S. G., S. A. C., and P. G. W. conceived the hypothesis, designed the study, and interpreted data. S. G. drafted the initial manuscript. P. G. W., S. A. C., M. K. H., J. L. C., R. G. B., E. R. B., R. P. B., A. C., C. B. C., G. C., M. T. D., N. N. H., R. P., J. A. K., S. P. P., A. T. H., F. J. M., W. K. O., D. J. C., and N. E. A. were involved in data collection and processing. All authors participated in manuscript editing for critical intellectual content and approved the final manuscript. S. G., S. A. C., and P. G. W. are guarantors of the manuscript and take responsibility for the integrity of the data and the accuracy of the data analysis.

Financial/nonfinancial disclosures: The authors have reported to CHEST the following: E. R. B. has undertaken clinical trials administered through his employers, Wake Forest School of Medicine and University of Arizona, for AstraZeneca, MedImmune, Boehringer Ingelheim, Cephalon/Teva, Genentech, Johnson and Johnson (Janssen), Novartis, Regeneron, and Sanofi Genzyme; he has also served as a paid consultant for AztraZeneca, MedImmune, Boehringer Ingelheim, Glaxo Smith Kline, Novartis, Regeneron, and Sanofi Genzyme, outside the submitted work. S. A. C. reports personal fees from AstraZeneca, nonfinancial support from Genentech, and grants from MedImmune, outside the submitted work. A. C. reports grants from the National Heart, Lung, and Blood Institute (NHLBI)/National Institutes of Health $(\mathrm{NIH})$, during the conduct of the study; grants from NHLBI/ $\mathrm{NIH}$, grants from National Institute of Environmental Health Sciences/NIH; and personal fees from VIDA Diagnostics, outside the submitted work. C. B. C. reports grants from Equinox Health Clubs, personal fees from Equinox Health Clubs, grants from Amgen, personal fees from PulmonX, other from GlaxoSmithKline, outside the submitted work; and part-time employment in scientific engagement for the GlaxoSmithKline Global Respiratory Franchise. D. J. C. reports grants from NHLBI/NIH, during the conduct of the study; and grants from COPD Foundation, outside the submitted work. G. C. reports grants from Boehringer Ingelheim, Novartis, AstraZeneca, Respironics, MedImmune, Actelion, Forest, Pearl, Ikaria, Aeris, PneumRx, and Pulmonx; equity interest in HGE Health Care Solutions, Inc.; and consultation for Amirall, Boehringer Ingelheim, and Holaira, outside the submitted work. J. C. reports grants from NHLBI/NIH during the conduct of the study; grants from National Institute of Allergy and Infectious Diseases/NIH, Department of Veterans Affairs, Department of Defense, and MedImmune Corporation, Ltd., outside the submitted work. M. T. D. reports grants from NHLBI, during the conduct of the study; and grants from Department of Defense, personal fees and contracted clinical trials from Boehringer-Ingeheim, GlaxoSmithKline, AstraZeneca, and Boston Scientific; contracted clinical trials from Novartis,
Yungin, PneumRx/BTG, and Pulmonx; and personal fees from Genentech, outside the submitted work. M. K. H. reports personal fees from GlaxoSmithKline, Boehringer Ingelheim, and AstraZeneca, and nonfinancial support from Novartis and Sunovion, outside the submitted work. N. N. H. reports grants and personal fees from AstraZeneca and GSK, grants Boehringer Ingelheim, NIH, and the COPD Foundation, outside the submitted work. A. T. H. reports grants from NHLBI and the Foundation for the National Institutes of Health, during the conduct of the study. J. A. K. reports grants from NIH/NHLBI, during the conduct of the study. F. J. M. reports grants from NHLBI, during the conduct of the study; personal fees and nonfinancial support from American College of Chest Physicians, AstraZeneca, Boehringer Ingelheim, Continuing Education, ConCert, Genentech, GlaxoSmithKline, Inova Fairfax Health System, Miller Communications, National Association for Continuing Education, Novartis, Pearl Pharmaceuticals, PeerView Communications, Prime Communications, Puerto Rican Respiratory Society, Chiesi, Roche, Sunovion, and Theravance; nonfinancial support from ProterrixBio; personal fees from Columbia University, Haymarket Communications, Integritas, Inthought Research, MD Magazine, Methodist Hospital Brooklyn, New York University, Unity, UpToDate, WebMD/ MedScape, Western Connecticut Health Network, and American Thoracic Society; and grants from NIH, outside the submitted work. R. P. III reports grants from NHLBI and COPD Foundation, during the conduct of the study; and grants from Department of Veterans Affairs, outside the submitted work. S. P. P. reports grants from NIH and NHLBI, during the conduct of the study. P. G. W. reports grants from NIH/NHLBI, during the conduct of the study; and personal fees from AstraZeneca, Theravance, Regeneron, Sanofi, Genentech, and Novartis, outside the submitted work. None declared (S. G., R. P. B., W. K. O., N. E. A.)

Role of sponsors: The sponsor had no role in the design of the study, the collection and analysis of the data, or the preparation of the manuscript.

Additional information: The e-Appendix, e-Figure, and e-Tables can be found in the Supplemental Materials section of the online article.

\section{References}

1. Vogelmeier CF, Criner GJ, Martinez FJ, et al. Global strategy for the diagnosis, management, and prevention of chronic obstructive lung disease 2017 Report. GOLD Executive Summary. Am J Respir Crit Care Med. 2017;195(5):557-582.

2. Regan EA, Lynch DA, Curran-Everett D, et al. Clinical and radiologic disease in smokers with normal spirometry. JAMA Intern Med. 2015;175(9):1539-1549.

3. Woodruff PG, Barr RG, Bleecker E, et al. Clinical significance of symptoms in smokers with preserved pulmonary function. N Engl J Med. 2016;374(19): 1811-1821.

4. Kesimer M, Ford AA, Ceppe A, et al Airway mucin concentration as a marker of chronic bronchitis. $N$ Engl J Med. 2017;377(10):911-922.

5. Fahy JV. Type 2 inflammation in asthma - present in most, absent in many. Nat Rev Immunol. 2015;15(1):57-65.

6. Christenson SA, Steiling K, Berge M van den, et al. Asthma-COPD Overlap. Clinical relevance of genomic signatures of type 2 inflammation in chronic obstructive pulmonary disease. Am J Respir Crit Care Med. 2015;191(7):758 766.

7. Couper D, LaVange LM, Han M, et al. Design of the Subpopulations and Intermediate Outcomes in COPD Study (SPIROMICS). Thorax. 2014;69(5):492495.

8. Gan WQ, Man SFP, Senthilselvan A, Sin DD. Association between chronic obstructive pulmonary disease and systemic inflammation: a systematic review and a meta-analysis. Thorax. 2004;59(7):574-580.

9. Hoenderdos K, Condliffe A. The neutrophil in chronic obstructive pulmonary disease. Am J Respir Cell Mol Biol. 2013;48(5):531-539.

10. Jones PW, Harding G, Berry P, Wiklund I, Chen W-H, Kline Leidy N. Development and first validation of the COPD Assessment Test. Eur Respir J. 2009;34(3): 648-654.

11. Kim V, Criner GJ. Chronic bronchitis and chronic obstructive pulmonary disease. Am J Respir Crit Care Med. 2013;187(3): 228-237.

12. O'Neal WK, Anderson W, Basta PV, et al. Comparison of serum, EDTA plasma and P100 plasma for luminexbased biomarker multiplex assays in patients with chronic obstructive pulmonary disease in the SPIROMICS study. J Transl Med. 2014;12:9.

13. Sun W, Kechris K, Jacobson S, et al. Common genetic polymorphisms influence blood biomarker measurements in COPD. PLoS Genet. 2016;12(8): e1006011.

14. Benjamini Y, Hochberg Y. Controlling the false discovery rate: a practical and powerful approach to multiple testing. $J R$ Stat Soc Ser B Methodol. 1995;57(1):289300.

15. Agustí A, Edwards LD, Rennard SI, et al Persistent systemic inflammation is associated with poor clinical outcomes in COPD: a novel phenotype. PLOS ONE. 2012;7(5):e37483.

16. Woodruff PG, Agusti A, Roche N, Singh D, Martinez FJ. Current concepts in targeting chronic obstructive pulmonary disease pharmacotherapy: making progress towards personalised management. Lancet. 2015;385(9979): 1789-1798. 
17. Sinden NJ, Stockley RA. Systemic inflammation and comorbidity in COPD: a result of 'overspill' of inflammatory mediators from the lungs? Review of the evidence. Thorax. 2010;65(10):930-936.

18. Wouters EFM, Reynaert NL, Dentener MA, Vernooy JHJ. Systemic and local inflammation in asthma and chronic obstructive pulmonary disease. Proc Am Thorac Soc. 2009;6(8):638-647.

19. Fabbri LM, Rabe KF. From COPD to chronic systemic inflammatory syndrome? Lancet. 2007;370(9589):797-799.

20. Sevenoaks MJ, Stockley RA. Chronic obstructive pulmonary disease, inflammation and co-morbidity - a common inflammatory phenotype? Respir Res. 2006;7(1):70.

21. Yanbaeva DG, Dentener MA,

Creutzberg EC, Wesseling G,

Wouters EFM. Systemic effects of smoking. Chest. 2007;131(5):1557-1566.

22. Emerging Risk Factors Collaboration, Kaptoge S, Di Angelantonio E, et al. $\mathrm{C}$-reactive protein concentration and risk of coronary heart disease, stroke, and mortality: an individual participant meta-analysis. Lancet. 2010;375(9709): 132-140.

23. Innes AL, Woodruff PG, Ferrando RE, et al. Epithelial mucin stores are increased in the large airways of smokers with airflow obstruction. Chest. 2006;130(4): 1102-1108.

24. Husebø GR, Bakke PS, Aanerud M, et al. Predictors of exacerbations in chronic obstructive pulmonary disease - results from the Bergen COPD Cohort Study. PLoS ONE. 2014;9(10): e109721.

25. Thomsen M, Ingebrigtsen TS, Marott JL, et al. Inflammatory biomarkers and exacerbations in chronic obstructive pulmonary disease. JAMA. 2013;309(22): 2353.

26. Keene JD, Jacobson S, Kechris K, et al. Biomarkers predictive of exacerbations in the SPIROMICS and COPD gene cohorts. Am J Respir Crit Care Med. 2016;195(4): 473-481.
27. Pinto-Plata VM, Müllerova H, Toso JF, et al. C-reactive protein in patients with COPD, control smokers and nonsmokers. Thorax. 2006;61(1):23-28.

28. Torres JP de, Cordoba-Lanus E, LópezAguilar C, et al. C-reactive protein levels and clinically important predictive outcomes in stable COPD patients. Eur Respir J. 2006;27(5):902-907.

29. Broekhuizen R, Wouters EFM, Creutzberg EC, Schols AMWJ. Raised CRP levels mark metabolic and functional impairment in advanced COPD. Thorax. 2006;61(1):17-22.

30. Rodriguez-Roisin R, Han MK, Vestbo J, Wedzicha JA, Woodruff PG, Martinez FJ. Chronic respiratory symptoms with normal spirometry. A reliable clinical entity? Am J Respir Crit Care Med. 2016;195(1):17-22.

31. Koo H-K, Vasilescu DM, Booth $\mathrm{S}$, et al. Small airways disease in mild and moderate chronic obstructive pulmonary disease: a cross-sectional study. Lancet Respir Med. 2018;6(8): 591-602. 